\title{
A Gramática como instrumento de conhecimento do real no Vākyapadīya de Bhartrohari: breve comentário a vp I.1-12*
}

\author{
Adriano Aprigliano ${ }^{1}$ \\ Universidade de São Paulo (Brasil)
}

Recibido: noviembre 4 de 2015 - Revisado: enero 15 de 2016 - Aceptado: febrero 5 de 2016

Referencia formato APA: Aprigliano, A. (2016). A Gramática como instrumento de conhecimento do real no Vākyapadīya de Bhartrhari: breve comentário a Vp I.1-12. Rev. Guillermo de Ockham, 14(1), 69-77. doi: http://dx.doi.org/10.21500/22563202.2310

\section{Resumo}

Es este artigo presento breve comentario de los doce versos iniciales del primer libro del Vākyapadīya de Bhartrọari (V d.C.), a fin de clarear la relación entre la ontología de brahma y el estatuto de la disciplina de la Gramática, Vyākarana, como instrumento de conocimiento de lo real.

Palavras-chave: Real, Veda, gramática, filosofia del lenguaje

\section{Grammar as an instrument for the knowledge of the real in the Vākyapadīya of Bhartrahari: a brief commentary on Vp I. 1-12}

\section{Abstract}

In this article I present a brief commentary on the first twelve verses of the first book of Bhartrihari's Vākyapadiya (V d.C.), in order to clarify the relationship between the ontology of brahma and the status of Grammar, Vyākaraṇa, as a means of knowledge of reality.

Keywords: Reality, Veda, grammar, philosophy of language

* Este trabalho dá prosseguimento a meus estudos da obra de Bhartrhari iniciados em minha tese de Doutorado: Aprigliano, A. (2011). O conhecimento da linguagem como herdado pela tradição gramatical indiana: a primeira seção do Vākyapadīya de Bhartrhari. São Paulo: FFLCH/USP. Tese de doutorado.); e continuados no estágio de Pós-doutorado intitulado Fontes do pensamento linguístico na Índia Antiga: o segundo livro da Tri-kāṇ̣i de Bhartrohari, texto, tradução e notas, concluído em 2013. A tradução o $1^{\mathrm{o}}$ livro do Vākyapadiya realizada para a tese foi publicada em forma de livro: Aprigliano, A. (2014). Da palavra [Vākyapadīya]. Sáo Paulo: Unesp.

1. Professor de Língua e Literatura Latina (FFLCH-USP). Mestre em Linguística (2006) e Doutor em Letras (2011) pela Faculdade de Filosofia, Letras e Ciências Humanas da Universidade de São Paulo (FFLCH/USP), Brasil. Pós-doutorado pela mesma universidade (2013). Correio eletrônico: aprigliano@usp.br. Endereço postal: Praça Franklin Roosevelt, 128, apto 1401, CEP 01303-020, Consolação, São Paulo/Brasil. 


\section{La gramática como instrumento de conocimiento de lo real en el Vākyapadīya de Bhartrthari: un breve comentario a Vp I.1-12}

\section{Resumen}

En este artículo presento un breve comentario de los doce versos iniciales del primer libro del Vākyapadīya de Bhartrhari (V d.C.), a fin de clarificar la relación entre la ontología de Brahma y el estatuto de la disciplina de la gramática Vyākarana, como instrumento de conocimiento de lo real.

Palabras clave: Real, Veda, gramática, filosofía del lenguaje

\section{Introdução}

A mais famosa tese que se tem atribuído ao Vākyapadīya (Vp) de Bhartrohari, seja pela tradição de comentadores antigos, seja pelos que retomaram o estudo da obra no período pós-colonial e moderno, é a de que o sentido linguístico (arthaḥ) radica não nas partes ou unidades do som ou fonemas (varṇāh, s. varṇah) nem do vocábulo (padam), mas em unidade maior, chamada vākyam, a frase ou enunciado. No âmbito dessa unidade maior, o sentido é uma entidade supra-analítica, não decomponível em partes. No entanto, a fim de compreender o alcance dessa tese, é preciso esclarecer o que entende por śabdah (palavra ou linguagem) a tradição intelectual indiana, e especialmente a escola especulativa que deriva da Gramática pāniniana. Decerto os contornos desse conceito tal como articulados pelos antigos pensadores indianos, em especial na obra do gramático Bhartrhari, não se coadunam com as noções modernas acerca da linguagem postuladas por linguistas e filósofos da linguagem.

É no primeiro livro do Vp que Bhartrhari constrói a ontologia de brahma por meio de proposta singular acerca da natureza desse real. Brahma, para Bhartrhari, é de natureza linguística, real verbal, quer em seu aspecto uno, quer em seu aspecto múltiplo, manifesto. Apenas parte do aspecto múltiplo é a linguagem tal como entendemos, manifesta em sons distintos ou articulados e aparentemente diversa dos demais componentes da realidade objetiva de que faz parte, ainda que detentora da capacidade especial de referir-se a eles e de com eles, de certa maneira, identificar-se. $\mathrm{O}$ aspecto uno do real é a linguagem como substrato da forma da consciência. Para conectar a forma linguística da consciência e a palavra manifesta, Bhartroari postula plano intermediário do funcionamento da linguagem, i.e., da relação entre linguagem e referente, em que a distinção ontológica entre palavra e coisa torna-se maleável e tende a diluir-se. Esse é o aspecto mental da linguagem. Na linguagem mental e interior, ainda que o indivíduo consciente distinga a relação entre a palavra como significante e o referente como significado em virtude da seriação, i.e., o aspecto sequencial ou linear decorrente do tempo, a forma de existência de ambos, significante e significado, é idêntica, já que ambos são de natureza mental, imaterial e, sendo assim, começam a confundir-se numa mesma substância. $\mathrm{O}$ aspecto uno do real será a contração desse tempo ainda presente na existência mental da palavra.

Essa breve exposição dos três aspectos ou planos da linguagem postulados no $\mathrm{Vp}$, exarada em metalinguagem moderna e abstrata, não deixa entrever os pormenores do texto de Bhartrhari que precisam e singularizam as categorias por ele empregadas. Refiro-me ao que por vezes é deixado de lado no tratamento das tradiçóes de pensamento segundo a concepção de uma philosophia uniuersalis, como se se tratasse não mais que de rebarbas da peça que sai do molde, ou de verniz que, por assim dizer, se dilui nos níveis conceituais mais abstratos. Entendo, porém, que esses mesmos pormenores sejam a própria essência dos fundamentos conceituais, i.e., do ponto de vista que tem Bhartrhari do seu objeto, e que esse ponto de vista, para aqui lembrar Ferdinand de Saussure, não é mera descrição ou entendimento singular de objeto compartilhado, mas estabelece objeto singular em comparação com outras tradições de pensar a linguagem.

A conveniência e abrangência do termo linguagem e a metalinguagem poderosa e universalista da tradição filosófica moderna podendo embaçar pontos embaraçosos do pensamento bhartrhariano, neste artigo, por meio de breve comentário aos versos iniciais do Vp (I.112), procuro explicitar as conexóes supramencionadas entre o real, brahma, o estatuto da palavra, śabdah, e a função da Gramática, Vyākaraṇa, como instrumento de 
conhecimento desse real. Faço-o, porém, procurando recuperar a singularidade dos fundamentos conceituais em que se baseia o pensamento desse autor, derivados de modelo tradicional de conhecimento, no âmbito do qual a Gramática cumpre a função primeira e primordial de disciplina auxiliar do processo de transmissão, preservação e interpretação - manipulação enfim - de corpus textual revelado, o Veda. Para a pormenorizaçáo do teor dos versos, apoio-me na Vākyapadīya-vrttti (Vp-v), comentário atribuído a Bhartrihari por alguns, a algum discípulo, por outros estudiosos (cf., e.g., Biardeau 1964, Bronkhorst 1988; Aklujkar 1993). Utilizo a versão crítica do texto tal como estabelecida por Rau (1977), para as müla-kārikāh (mk), e por Aklujkar, para a Vp-v, esta última ainda não publicada, a que tive acesso por intermédio do editor.

\section{Comentário a Vp I.1-13}

\section{I.1ab an-ädi-nidhanaṁ brahma śabda-tattvam yad akșaram}

O primeiro verso é o postulado metafísico que permeia toda a obra: o real, brahma, é descrito como algo que supera o tempo (an-ädi-nidhanam), como um eterno (akșaram), tratando-se, portanto, de ideia já conhecida acerca do real suprassensorial que remonta às especulaçôes das Upanișad (circa VI a I a.C.). Mas o real é, ainda, śabdatattvam, i.e., algo cuja natureza, quididade ou realidade (tattvam) é palavra (śabda-). Trata-se, portanto, de real verbal ou linguístico suprassensorial. Leio o composto sabda-tattvam

como um karma-dhärayah copulativo - i.e., no qual os membros são nomes em relação de identidade - empregado como bahu-vrïhih (composto exocêntrico, qualificativo) de brahma: "brahma cuja realidade é verbo". Também é possível lê-lo como composto do tipo tat-purușaḥ genitivo. Neste caso, a relação genitiva daria a entender que brahma é "a realidade da palavra/linguagem”, aquilo que na linguagem é real (sabdasya tattvam yad). Ambas as ideias são conceptualmente corretas na perspectiva ontológica de Bhartrhari. Neste segundo caso, basta pensar na estratificação de śabdạ nos três planos aludidos na introdução, vaikharì, madhyamā e paśyantī (cf. Vp I.159-170). A "realidade da linguagem" seria, aí, a forma pura de $v \bar{a} k$ (= śabdah), paśyantì, na qual toda diversidade se reabsorveu, o que a torna idêntica a brahma, como real verbal imanifesto. Cf., e.g., o que diz a Vp-v I.159, ao explicar o termo paśyantī:

pratisamihrta-kramā saty apy abhede samãvista-kramaśaktịh paśyantī. Sà calācalā pratilabdha-samādhānà cāvrrtā viśuddhā ca, saminivișta-jñeyākārä pratilīnākārā nirākārā ca, paricchinnārtha-pratyavabhäsā samssștārtha-pratyavabhäsā praśänta-sarvārtha-pratyavabhāsā cety aparimāna-bhedā. "Vidente (paśyantī) é aquela em que a seriação se reabsorveu, mas que, mesmo na indiferenciação, a possui in potentia. Ela ora é flutuante, ora está em repouso; ora é contaminada, ora é pura; ora residem nela as formas dos objetos cognoscíveis, ora nela essas formas se dissolvem, ora não há qualquer forma; ora os reflexos dos objetos nela se mostram distintamente, ora se dissolvem, ora cessam completamente. Tais são suas inumeráveis formas.”

\section{I.1cd vivartatèrtha-bhävena, prakriyā jagato yatah.}

Esse real, último e verbal, manifesta-se múltiplo ( $v i$ vartate) como ou sob a forma de arthāḥ (artha-bhävena). Arthah significa tanto o objeto-referente dos sentidos físicos (vastv-arthah) como o objeto-referente da palavra ou linguagem (śabdārthah). O autor se aproveita da ambiguidade semântica do termo arthạ para exprimir a diluição dessa diferença quando a manifestação é observada do ponto de vista da unidade. Essa manifestaçáo múltipla de brahma é a criação ou produção (prakriyā) do mundo (jagat) que experimentamos (prakriyā jagato yatah, "a partir do que a produção o mundo").

\section{I.2a ekam eva yad ämnātam,}

O real verbal, brahma, é uno (ekam). Sabemo-lo uno, pois foi assim transmitido pela tradição. Ämnātam, que em princípio significa "lembrado ou transmitido" (raiz $m n \bar{a}$, cf. gr. $m n \bar{e})$, tem sentido restrito ao âmbito em que se faz a transmissão. Mais adiante, em I.5, Bhartrhari menciona o Veda (vedaḥ, pl. vedāḥ), o que não deixa dúvida sobre a filiação das ideias expressas no $V p:^{2}$ é no âmbito do vedismo ou bramanismo que se transmite o Veda como sendo uno.

2. São inúmeros os passos do Vp que traem sua extração bramânica, especialmente o conhecimento que apresenta o autor das minúcias da exegese ritual tal como desenvolvida pela Mīmāmsā, a escola de exegese do rito. A cronologia mais aceita acerca da formação das escolas filosóficas indianas coloca a Mīmāmsā nos primeiros séculos da era Cristấo. Śabara, autor do influente Śabara-bhāṣya, comentário ao Jaimini-sūtra, deve ter sido contemporâneo de Bhartrorhari ou pouco anterior. Seja qual a conexão de Bhartrohari com a escola Mīmāmsā, com a qual compartilha muito pontos de vista, sua posição em relação ao Veda destoa das posiçóes comumente defendidas pelos mīmāmsaka. Embora se possa dizer com segurança que o Vp se filia a tradiçáo bramânica e parte de postulados sobre a natureza do Veda compartilhados por vertentes do vedismo de vários períodos, de maneira geral, nada de concreto e sabe sobre a pessoa do autor. Pela familiaridade com a exegese ritual é de supor que era brâmane, náo necessariamente sacerdote profissional. Sua conexão primeira é com a Gramática de Pāninini (V a.C.). Comentou o Mahābhāṣya de Patañjali (II a.C.), obra de que chegou a nós apenas fragmento do $1^{\circ}$ livro. 


\section{I.2b (...) bhinna-śakti-vyapäśrayāt,}

I.2cd aprthaktve'pi saktibhyah prthaktveneva vartate. A ideia de que brahma se apoia em diferentes poderes (bhinna-śakti-vyapāśrayāt), entendo que seja recurso para conceptualizar a flutuação entre identidade e diferença no processo de manifestação: Brahma, "embora não se distinga dos poderes, manifesta-se como se deles distinto fosse (I.2cd) ". Śaktibhyah em I.2c, abl. pl. de saktih, está colocado no centro de dois sintagmas e deve ser lido com ambos: i. aprthaktvépi śaktibhyah, ii. śaktibhyah prthaktveneva vartate. Os poderes são ao mesmo tempo identidade como constituição do real e diferença como sua potência de manifestação. A Vp-v I.2b de fato diz que em brahma (loc. brahmaṇi) estáo acumulados (samuccitāḥ) poderes (śaktayah) a ele contraditórios (virodhinyaḥ) e idênticos (ätma-bhütāh): bhinna-śakti-vyapäśrayāt: ekasyāvirodhena sabda-tattve brahmaṇi samuccitā virodhinya ätma-bhütāh śaktayah. Em seguida, a $\mathrm{Vp}$-v propóe interessante analogia entre a identidade e diferença das modificaçōes (vikārāh cf. Vp 1.3c) em brahma e a identidade e diferença dos objetos dos sentidos na percepção ou apreensão (upalabdhih ). Upalabdhih aqui refere-se à forma interna momentânea do que é apreendido, espécie de "tela" da consciência, na qual a multiplicidade apreendida são reflexos feitos duma mesma substância, idêntica à "superfície" refletida, a qual, mesmo abarcando quaisquer que sejam os reflexos do exterior, permanece sempre a mesma: tad yathä: bhinnārtha-pratyavabhāsa-mātrāyām ekasyām upalabdhāv arthākēra-pratyavabhāsa-mātrāḥ 'prothivī', 'lokā' iti. Um recorte ou identificação de parte dos reflexos apreendidos (avagrahaḥ), e.g., a identificação de que na apreensão de certa terra ( $p_{0}$ thivin) há uma árvore (vrksaḥ), não está em contradiçáo com o caráter uno da cognição (na... jñannasya ekatvena virudhyate), i.e., toda diversidade existente na apreensão de algo complexo como 'terra' não modifica o caráter uno da cognição desse objeto: na hi jñeya-gato vrksädy-äkärāvagraho jūānasyaikatvena virudhyate. Tal como no funcionamento da cognição (jñānam), a derivaçáo ou diversificação (prakriyā, vivartah), ainda que efeito do real, não o modifica em sua forma última; é, de certa forma, realidade secundária dependente de sua origem, os poderes constitutivos da unidade de brahma: prthaktvene vartate, "[brahma] manifesta-se (múltiplo) como se [deles] distinto fosse".

\section{I.3ab adhyāhita-kalām yasya kāla-śaktim upāśritāḥ,}

Dentre os poderes de brahma, o primeiro responsável pela diversificação é käla-śaktiḥ, o poder do tempo. Todo um capítulo é dedicado no livro III do Vp (cf; III.9) ao conceito de tempo, tal como compreendido em várias tradições anteriores e contemporâneas ao Vp. A Vp-v chama ao tempo svātantryam, independência ou autonomia. Em I.3a diz-se que ele, o poder do tempo, contém em si partes (adhyāhita-kalām, i.e., adhyāhitāḥ kalāh yasyām). Essa expressão, no meu entender, exprime o poder totalizador, compreensivo ou universal do tempo. Cf. Vp-v I.3 kälakhyena hi svätantryena sarvāh para-tanträ janmavatyạ śaktayaḥ samāviștāḥ kāla-śakti-vrttim anupatanti.

\section{I.3cd janmādayo vikārāḥ șad bhāva-bhedasya yonayaḥ.}

As partes ou particulares desse poder universal são os poderes em sua diversidade e, destarte, dependência (päratantryam), i.e., as modificações que dele dependem (upaśritāḥ... vikārāh șaț). O poder do tempo (käla-śaktih), como geral ou universal, é o responsável pela instauração primeira da existência ou de cada existente (bhāvaḥ), bem como substrato e critério dos demais poderes. Bhartrohahi representa esse caráter fundamental da função do tempo por meio da referência ao movimento essencial da existência comum, a saber, a vida do nascimento à morte (janmädayo vikārāh șaț). O tempo, portanto, independência ou autonomia que seja, é-o no plano da manifestação, já que do funcionamento dele dependem os demais poderes. Que seriam os demais poderes? Justamente tudo o que se pode pensar como substrato da multiplicidade. As seis modificaçóes a que se refere o verso são movimentos específicos dependentes do tempo, resultado desses poderes não nomeados. O passo é clara citação do Nirukta de Yāska (séc. V a.C.). Diz Yāska, citando Vārșyāyaṇi: șaḍbhāva-vikārā bhavantìti vārsyāyaṇih: jayatésti viparinamate vardhate’pakșìyate vinaśyatìti (Nir. I.2). "Vārșyāyaṇi diz que são seis a modificaçóes da existência/dos existentes, a saber, nascer, modificar-se, crescer, decair, morrer." No trecho que segue Yāska explica o teor de cada termo. Nem as $\mathrm{mk}$ nem a Vp-v dão ideia mais específica do que sejam esses poderes. Como indiquei acima, penso que sejam nada mais que o substrato que se puder nomear a todas as formas de manifestação, tais como as que Vārșyāyaṇi reduzira a seis. Essas modificaçóes, que têm por substrato os poderes dependentes do tempo, são a fonte da multiplicidade da existência (bhäva-bhedasya yonayah).

\section{I.4ab ekasya sarva-bijjasya yasya ceyam anekadhā} O tempo é, portanto, o maior responsável pela condição de existência comum, iyam anekadhā ... sthitih (cf. I.4d), a realidade tal como derivada da "semente una de tudo" $($ ekah sarva-bījah $=$ brahma $)$.

\section{I.4cd bhoktr-bhoktavya-rüpena bhoga-rūpena ca sthitih.}

O que caracteriza a existência múltipla de brahma é sua divisão em três categorias ou formas (rüpūnịi, s. rüpam), sujeito, objeto e experiência (bhoktä, bhoktavyam, bhogah). 
O sentido literal desses termos remete ao campo semântico da fruição: fruens, fruendum, fruitio. É deveras antigo o uso do conceito de fruição para representar a experiência da existência ordinária. É provável que derive dos debates do período das Upanișad (circa VI-III a.C.), marcados pelo ideal da renúncia à experiência mundana. A fruição identificava-se tanto aos aspectos básicos da subsistência, relativos à alimentaçáo (sentido primeiro da raiz bhuj), como aos aspectos mais complexos, relativos ao gozo dos prazeres mundanos (sentido secundário de bhuj). O mumukșuh, o que desejasse a libertaçáo (mokșaḥ), devia compreender a experiência da existência isenta da relação de sujeito e objeto. $\mathrm{Na}$ Kațha Upanișad (KU; circa III a.C.), e.g., Morte (Yama) oferece a Naciketas o gozo de todos os prazeres mundanos (ye ye kāmā durlabhä martya-lokel sarvān kāmāms chandataḥ prärthayasva. KU I.1.25ab), a fim de afastá-lo do conhecimento do mistério da morte (naciketo, maranaṁ mānupräkșīh. KU I.1.25f). Nesse texto, a renúncia ao prazer mundano, ícone da prisão da dualidade, marca a primeira barreira ou medo que se deve superar para superar a morte. De fato, na ordem da narrativa, é justamente essa renúncia de Naciketas no fim do primeiro capítulo (cf. KU I.1.26-29), esse enfrentamento do personagem Morte, que marca o assentimento desta em expor-lhe a doutrina do $\bar{a} t m \bar{a}$, o existente uno eterno, cf. KU I.2.

\section{I.5ab prāpty-upāyo’nukāraś ca tasya vedo maharșibhih,}

Diluída a unidade do real verbal, śabda-tattvam brah$m a$, na realidade fenomênica, persiste dele um símbolo ou imagem (anukāraḥ) em forma de linguagem, em princípio um bhoktavyam, fruendum, i.e., objeto dos sentidos. O conceito de anukāraḥ é um dos pontos embaraçosos da filosofia de Bhartrihari, pois se funda na ideia de revelaçáo pela palavra de ordem última e universal (dharmah). Os agentes dessa revelaçáo, os maharșayah (ou apenas rșayaḥ, s. rșihh), sábios do tempo antigo, têm acesso à visão imediata do dharmah. Eles transmitem-na aos que dela não têm acesso sob a forma de bilmah. Bilmah é termo de sentido obscuro, porém é o mesmo que anukārah, portanto é o vedạ em sua condição de reflexo, imagem ou réplica da ordem última. Essa ideia, Bhartrohari toma-a também ao supramencionado Nirukta de Yāska. Cf. Vp-v I.5: āha khalv api: sākșāt-krota-dharmāna rssayo babhūvuh. téperbhyo'säkșät-krta-dharmabhya upadesena mantrān sampräduh. upadésáya glāyanto’pare bilma-grahanayemam grantham samāmnāsișur vedam ca vedāngāni ca... (Nir. I.20) iti. Mas qual a relação entre o dharmah e brahma? $\mathrm{O}$ ponto de contato entre um e outro é o Veda, anukārah de brahma, na terminologia de Bhartrhari, e bilmah (anukäraḥ) do dharmaḥ, na terminologia de Yāska. Ora, o dharmah, ordem última - necessariamente serial, linear -, sob a forma do Veda, é o aspecto linguísticofenomênico de brahma, realidade última, não linear, de natureza verbal.

O Veda é, ademais, meio ou expediente de obtenção (prāpty-upāyaḥ), i.e., de recuperação do real, da unidade imanifesta. De fato, segundo a Vp-v I.5a, a obtenção de brahma significa nada mais que a superação das amarras (granthịh) do senso de eu (aham-kāraḥ), marcados na linguagem pela expressão do sujeito (aham) e do objeto (mama): mamāham ity ahamkära-granthi-samatikramamātram brahmaṇaḥ präptih. Também se expressa aí, em seguida, a mesma ideia sob outro ponto de vista, dizendo-se que é o retorno das modificaçôes à condição de origem, i.e., à condição de unidade: vikārānāàm prakrtibhäväpattih. Mas como o Veda funciona como instrumento de recuperação da unidade original?

\section{I.5cd eko'py, aneka-vartmeva samämnätah prothak prthak.}

Veda, aqui no singular (vedaḥ), recupera a dimensão unitária $(e k o p i)$ da multiplicidade verbal expressa no conjunto de textos transmitidos oralmente (samāmnātah) pelos antigos sábios-videntes. O Veda é a fundação das práticas rituais e intelectuais da tradição bramânica. Essa multiplicidade de textos se manifesta sob hierarquia que será explicitada nos próximos versos, a saber: em I.6 Śruti, em princípio as coleçôes védicas (sambitäḥ), inclui ademais Brāhmana, Āranyaka e Upanișad, primeira forma de exegese da tradição litúrgica; em I.7. Smṛti, corpus variado de obras auxiliares do ritual védico, como os Śrauta- e Grinya-sūtra, os Vedānga, disciplinas auxiliares do Veda, dentre as quais a Gramática, Vyākaraṇa, e obras do corpus jurídicos tais como o Mānava-dharma-s̄āstra; e em I.8. Artha-vāda, sentenças da Śruti isoladas e tomadas como fonte de debate intelectual e conceitual, bem como os próprios debates ou discursos (pravādāhn) de monistas e dualistas (ekativinām dvaitinām ca).

\section{I.Gab bhedānām bahu-mārgatvam̉ karmaṇy ekatra} cāngatā,

\section{I.Gcd śabdānām yata-śaktitvami tasya śākhāsu drósyate.}

As coleçôes de textos que compóem a Śruti ao longo do tempo foram transmitidas por diversos grupos ou escolas (śäkhāḥ, lit. "ramos"), em diversas recensōes (bhedānām bahu-mārgatvam), apresentando pequenas variações no emprego e no sentido de determinados termos (śabdānām yata-śaktitvam). Na diversidade dos ramos do Veda (tasya śäkhāsu drósyate), o elemento central, porém, o rito, permaneceu, uno (karmaṇy ekatra cāningatā), pois os ritos tal 
como praticados pelos ramos são um único rito enquanto fundamento da ordem do mundo, que é una, dharmah. A Vp-v a I.6b tenta dar conta dessa ideia por meio de simples analogia: um único rico resulta de todos os ramos, assim com um único tratamento resulta de todos os ramos da medicina: karmaṇy ekatra cāngatā: sarva-sákhā-pratyayam ekam் karma. tad yathā: sarva-bhișak-śäkhä-pratyayam ekam cikitsitam. A ideia de unidade decorre da função do rito ou do tratamento médico: em qualquer de suas formas, este deve curar a doença, aquele, suster a ordem.

\section{I.7ab smrtayo bahu-rüpaś ca drșțädrsțta-prayojanāh}

O segundo grau dessa hierarquia cuja função primordial é a manutenção da ordem (dharmaḥ), são as coleções a que se dá o nome coletivo de Smrrti ou Tradiçóes. As Tradiçóes, pelo que se entende a partir da $\mathrm{Vp}$-v, incluem todos os dispositivos, de base verbal e não verbal, que regulam o comportamento social do indivíduo, baseados no exemplo de uma elite (sisțtăhn). A Vp-v faz referência ao tratamento médico (o cuidado com a saúde), a hábitos alimentares apropriados, ao uso apropriado da linguagem, ao comportamento sexual apropriado e à pena por comportamento faltoso (e.g., a execuçáo opcional de rito expiatório por matar uma rã). Vp-v I.7b: drsțta-prayojanāśs cikitsitädi-vișayah. adrșta-prayojanā bhakșyäbhakșyagamyägamya-vācyāvacya-vișayāh. (...) avipratipattau tu sissțānām, drsța-prayojana-sambhavépi sati, vikalpa eva. tad yathā: maṇụūka-vadhe prāyaścitasya.

\section{I.7cd tam eväsritya lingebhyo vedavidbhịh prakalpitāḥ.}

Essas Tradiçôes são concebidas, formuladas (prakalpitāḥ̆) com base em indicaçōes (lingam, pl. lingāni) contidas no Veda ou Śruti, i.e, no primeiro nível hierárquico dos sustentáculos do dharmah, A elite mencionada no comentário — o termo śisțta lit. significa culto, instruído — são, na mk, os vedavidah (s. vedavid), conhecedores do Veda, responsáveis por essas formulaçôes. A participação nesse grupo é restrita: o indivíduo agente dos ritos prescritos pela tradição, ritos que sustentam uma única ordem, é mesmo (kartr-sämänyam) que se conduz de maneira apropriada tendo por guia as Tradiçôes. Cf. Vp-v I.7c: tam evāśritya lingebhya iti. śruty-äśritāni lingāni śruti-vihitānām smrtivihitānām ca karmaṇām kartros-sāmānyam prevedayante.

\section{I.8.ab tasyārtha-vāda-rūpāṇi niśritāḥ sva-vikalpajāḥ}

I.8cd ekatvinām dvaitinām ca pravādā bahudhāgatāḥ.

Afora o elemento prescritivo que apresentam Śruti e Smrrti verbais e não verbais, ainda outra forma de conhecimento indireto do dharmah se extrai do primeiro grupo de textos, o Veda ou Śruti. São os chamados artha- vādāh, sentenças extraídas do Veda que fundamentam, ao menos na perspectiva da $\mathrm{Vp}$-v, elaboraçóes de cunho esotérico, os discursos (pravādāhh) de dualistas e monistas. Não se precisa se o exercício exegético desses grupos de pensadores fica restrito à mesma elite que arregimentara as Tradições. Seja como for, é interessante notar que esses discursos monistas ou dualistas são fruto do vikalpạ̣ dos indivíduos envolvidos (sva-vikalpajāh... pravādāha). Vikalpah tem o sentido primeiro de opção na execução de prescriçôes rituais: é a possibilidade de decisão que resulta do debate entre ritualistas, no âmbito da ação ritual, e a elite social, no âmbito da ação comum (sempre ritualizada, como se pode já compreender). Fora do ambiente ritualista, o sentido de diferença ou diversidade é aplicável a esse termo, entre outros. A Vp-v especifica tratar-se de purușa-buddhi-vikalpah. Seria "a diversidade do intelecto humano"? Ou a expressão tem sentido menos preciso, significando algo como "o pensar diferente dos homens", ou ainda a "diferença no intelecto humano", significando mais claramente a ideia de capacidades diferentes? A exposição da Vp-v I.8 aponta para a $1^{\text {a }}$ ou $2^{a}$ opção, uma vez que apenas apresenta rol de artha-vādāh extraídos do Śatapațha-brāhmaṇa, Rog-veda e Taittirīya-brāhmaṇa explanados de diferentes pontos de vista, primeiro monistas e em seguida dualistas, além de um terceiro, que parece provir de algum tipo de monismo cum dualismo baseado em artha-vädah extraído do Yajur-veda.

I.9ab satyā viśuddhis tatroktā vidyaivaika-padāgamā

\section{I.9cd yuktā praṇava-rüpeṇa sarva-vädāvirodhinā.}

Os discursos supramencionados, que se fundam nos artha-vādāh do Veda, têm justamente a brahma por objeto, o mesmo real verbal uno. Sua diversidade resulta do fato de que brahma, estando além de toda diversidade (sarva-vikalpätite), contém si todos os poderes (sarvasakti-yogāt) e todas as formas (sarva-rüpe; cf. Vp-v Ad I.9 e I.9a). Ora, em brahma, um discurso não se distingue de outro discurso a que se cria contrário: ihaikasmin sarva-rūpe brahmani yo darśana-parikalpah sa viruddharüpäbhimatebhyo darśana-parikalpäntarebhyo na bhidyate. Brahma é śabda-tattvam, destarte, é o universal da palavra, śabdatvam. Essa pureza (viśuddhih ), que não conflita com nenhum discurso (sarva-vādāvirodinā), está atrelada à forma do pranava (yuktā praṇava-rūpeṇa), a sílaba om. Em que sentido brahma, como śabda-tattvam, é o om? A Vp-v I.9cd responde que o pranavah contém a forma de todas as palavras articuladas (sarva-śruti-rüpah; cf. o sentido técnico de śruti aqui), é prakrti-sarvanāma, "o pronome, a dêixis de prakrtih", i.e., da forma original de brahma. Essa relaçáo expressa em dualidade o uno apenas

$74<$ Universidad de San Buenaventura, Cali - Colombia 
figurativamente, por necessidade da articulação verbal in actu. O critério ontológico garante a unidade do entre signo e referente.

I.10ab vidhātus tasya lokānām añgopānga-nibandhanā O Veda, aqui idêntico ao pranavaḥ, é o lokānām vidhātā, criador/ordenador do mundo, pois, como anukärah de brahma, é origem mesma e, como bilmah, imagem do dharmah, assume a forma de instrutor: Vp-v I.10: vedo hi lokānām prakrtitvena copadeștr-rüpatvena ca vivarteșu [ca] vyavasthäsu ca vidhātā.

\section{I.10cd vidyä-bhedāḥ pratāyante jñanna-samiskära-hetavah.}

Em todas as formas manifestas do real verbal, e em todas a variáveis dessas formas (cf. citação da $\mathrm{Vp}$-v acima: vivarteșu [ca] vyavasthāsu ca), os membros do Veda (añgāni), sub membros (upāngāni) e de demais ciências (-nibandhanā vidyā-bhedāh) conexas ou dependentes cumprem o papel de aperfeiçoar o conhecimento humano (jñāna-samkāra-hetavah). $\mathrm{Na} \mathrm{Vp-v,} \mathrm{apesar} \mathrm{de} \mathrm{algumas}$ lacunas, conseguimos vislumbrar o rol de ciências auxiliares, os membros (añgāni) do Veda, que pertencem à categoria maior de Smrti, e incluem "Jautișa (Astrologia) etc.", i.e., como toda probabilidade a lista tradicional de seis vedāngāni, contendo ainda Śikṣā (Fonética), Chandas (Métrica), Vyākarana (Gramática), Nirukta (Etimologia) e Kalpa (Ciência do ritual). Quanto aos submembros, a Vp-v dá testemunho problemático, ao separar a Śruti do Trayyanta (i.e., as Upanișad), dando a entender, pela ordem dos termos nos compostos nominais, que este é upāngam: praṇavāngopāngebhyaśs ca śruti-smrtitrayyantädibhyo vidyä-bhedāh prabhavanti. Outro passo pouco satisfatório é a identificação das diferentes ciências (vidya-bhedah) derivadas do Veda, de seus membros e submembros. O passo, tal como editado por Aklujkar, aponta mais de uma lacuna possível, além de dúvidas quanto a certos termos. Seja como for, o único nome de ciência ou saber mencionado como exemplo não é claro: svapna-vipäka-yoni-jñannädayaḥ, seria cada membro do composto o nome de um saber? Subramania-Iyer (1966) apenas utiliza a expressão dream-lore, decerto na tentativa de reconstituir svapna-jñānam smas não comenta outras possibilidades.

I.11ab äsannaṁ brahmaṇas tasya, tapasām uttamam tapah,

Ainda que não se possa, a partir da forma do texto das mk e da Vp-v, fixar com exatidão qual teria sido a classificação das ciências derivadas dos membros e submembros do Veda, mesmo assim a Gramática sempre ocupa posiçáo de Vedānga ou Smrati. Aqui Bhartrohari chama-a próxima de brahma (äsannam brahmanas tasya), e a Vp-v glosa: de śabda-brahma, o brahma-palabra, i.e., o Veda como forma manifesta do real verbal. A gramática é próxima de brahma porque atua como auxiliar direta (säkșäd upakāri) no aperfeiçoamento da forma própria do brahma-palavra que serve à aquisição da correção. Vp-v I.11: śabda-brahmaṇo yatah sva-rüpa-samskärah sädhutva-pratipatty-arthaḥ tad àsannam säkșäd upakāri. O que seja esse auxiliar diretamente, a Vp-v explica-o tomando como exemplo a ciência da substituição, ūhaḥ, mencionada no Mahābhāṣya de Patañjali (II a.C) dentre os objetivos precípuos (prayojanāni) da Gramática: kāni punaḥ śabdānuśásanam prayojanāni? rakșa_üha_ägama-laghu_asandehāḥ prayojanam, Mbhās I.I.14). Ūha é previsão e provimento das modificações das formas gramaticais a serem adaptadas a passagens de textos ritualísticos em diferentes contextos. É função do ritualista (yajña-gatah). Porém o ritualista e o gramático (vaiyakaraṇaḥ) se confundem na visão de Patañjali: a Gramática é o instrumento sine qua non do conhecimento do ritualista: sarvair lingair na ca sarväbhir vibhaktibhir mantrā nigaditāḥ. te cāvaśyam yajña-gatena yathäyatham viparinamayitavyāḥ. tān nāvaiyäkaranạ saknoti yathäyatham viparinamayitum. tasmäd adhyeyam vyākaraṇam (Mbhāṣ I.1.16-18). A Gramática tem, portanto, acesso imediato à matéria verbal do Veda, e o gramáticos é aquele que tem ou arroga-se a prerrogativa nấo só de guardar e transmitir (cf. rakșaḥ e ägamaḥ, no rol supracitado), mas também de manipular, ritualista por excelência, essa matéria, essa "massa de brahman" (brahmarāsih h, cf. MBhāṣ I.36.18). Em virtude desse contato imediato com o Veda como matéria, o oficio da gramático, como studium, esforço especial, supera as demais asceses (tapasām uttamaṁ tapaḥ). Essa superação se funda no testemunho da tradição. Transmite a tradição que o mero conhecimento do akșara-samāmnāyah, o conjunto dos fonemas, rol anexo a Gramática de Pānini, é uma forma de ascese, que dá frutos especiais, "os mais puros frutos de todos os Veda": Vp-v I.11b: yasya akșara-samāmnāyasya jñäna-mätreṇa sarva-veda-punya-phalāväptir ägamena smaryate.

\section{I.11cd prathamam chandasäm añgam ähur vyäkaraṇàm} budhāh.

Concluindo o raciocínio acima enunciado, a Gramática é primeiro dos vedāngāni, as disciplinas auxiliares do Veda (prathamam chandasām añgam). Das seis disciplinas mencionadas, quatro lidam com matéria verbal (Fonética, Métrica, Gramática e Etimologia). No âmbito da transmissão tradicional dessas disciplinas, é possível que cada chefe de escola tenha dado proeminência à sua. A Vp-v não justifica o uso do plural em āhur vyākaranam budhāh 
(dizem os sábios acerca da Gramática), de modo que seria apenas um plural de respeito, comum em sânscrito, pois foi de fato Patañjali, a quem a Vp-v se refere, quem se pronunciou a posição da gramatica entre os vedāngāni: evam hy āha: pradhānam ca șațsv añgeșu vyākaraṇam. pradhäne ca krto yatnah phalavān bhavatìti.

\section{I.12ab prāpta-rūpa-vibhägāyā yo vācah paramo rasaḥ}

I.12cd yat tat punyatamam jyotis tasya märgo'yam ānjasaḥ.

Dada sua posição mais próxima das formas de existência do real verbal, a Gramática é a via direta (mārgo’yam ānjasaḥ) à seiva ou essência suprema (paramo rasaḥ) da linguagem (vācah). A linguagem, como vimos, é, em toda sua extensão - śabda-tattvam brahma - real verbal que assume diferentes formas (präpta-rūpa-vibhāgāayāhh). A Vp-v I.12ab explica esse assumir diferentes formas de duas maneiras. 1. A linguagem, real verbal, una, não linear, interior, assume a forma dos objetos verbais, varṇah, padam e vākyam por meio da distinção dos pontos de articulação etc.: abhinnāt samihrta-kramäd antasaminiveśinah śabda-tattväd varṇa-pada-vākya-lakșanam rüpa-vibhägam sthānädi-bhedena präptāyà vācah. 2. A linguagem, real verbal etc., assume diferença de forma adicional (upagrahah) em vacas etc. como referentes: abhidheyatvena vā gavādi-rūpa-pravibhägopagraham nityenārtha-sambandhena präptāyā vācaḥ. A ideia expressa pelo termo upagrahaḥ é a da precedência da existência da substância verbal em relação à categoria dos referentes. Essa precedência táo-somente respeita a ordem da manifestação do sutil ao crasso, subentendida na relação e o uno e o múltiplo. Se o uno é verbo, o verbo precede a coisa, que é forma final, crassa, do verbo.

Se é linguagem, portanto, toda a extensão do real, de palavras a coisas, a Gramática é a via direta (märgah ānjasaḥ) ao feixe mais puro de toda essa extensão: a porção correta da linguagem, que significa diretamente e é fonte de elevada existência mundana (paramo rasa iti vācakatvād abhyudaya-hetutvāc ca vyavasthita-sädhubhāvah śabda-samūho'bhidhiyate; Vp-v I.12b); é via direta, ademais, à "luz mais pura" (punyatamaṁ jyotis), metáfora da consciência. A Vp-v cita passo náo identificado, que fala da "luz (prakäśa h = jyotis), chamada palavra (śabdäkhyah), que ilumina o que tem e o que não tem luz (consciência individual); a ela se prende tudo isto (o mundo fenomênico), tudo quanto é material e imaterial, móvel e imóvel”. Vp-v I.12c (...) yaś ca prakāsáärakāśayoḥ prakāsayitã śabdākhyaḥ prakāśạ̣, tatraitat sarvam upanibaddham yāvad vastv avastu, yāvat sthāsnu carișnu ceti.

O método gramatical baseado em regras que contêm o geral o particular é via breve (laghunopàyena) para aquisição da totalidade de śabda-brahma: Vp-v I.12d: sāmänya-viśeșaddhi lakșaṇam lakșaṇa-prapañcābhyām krtsnasya śabda-brahmaṇo laghunopāyena samadhigamanimittam. O conhecimento do sistema de regras da Gramática permite, ademais, inferir a existência dos sișțāh que, sem instruçáo, na forma da luz da consciência (labdha-jyotișām), se uniram à forma pura e sem desvios de sabda-brahma: Vp-v I.12d (...) upadeśam cāntareña samiskāravati nirapabhramise śabda-brahmaṇi labdha-jyotișāmỉ sișțānām anumānam. Esses sișțāḥ parecem ser os mesmos rsith citados no Nirukta (cf. acima I.X), que haviam tido a experiência direta do dharmạ̣ (säkșäd-dharmānaḥ rșayaḥ). A Gramática será, portanto, a instrução (upadeśạ̣, anuśásanam), capaz de conduzir o indivíduo, gramático-ritualista, a condição de pureza dos antigos rșayah.

\section{Conclusão}

O conceito de linguagem que se vem constituindo desde o início deste comentário radica em entendimento singular da natureza do real. Trata-se de real verbal, que, por sua vez, mais que residir na consciência dos indivíduos, constitui sua própria forma. A percepção da condição de existência como uma consciência independente de substância verbal (cf. vāg-rūpatā avabodhasya em Vp I.132), deriva, ao que tudo indica, de especulaçōes sistemáticas acerca da experiência de conhecimento atribuída aos rși do passado e aos homens no tempo de Bhartrhari responsáveis pela manipulação do Veda associada à execução dos ritos. Nessa tradiçáo todos os atos da vida que instauravam e sustentavam a ordem (dharmah), atos rituais por excelência, mais que marcados pela palavra ritual (vedah), eram mesmo identificados a ela. A experiência fenomênica da palavra múltipla, portanto, deriva de um real verbal uno e não linear, que assumiu primeiro diferença na matéria sutil do pensamento e depois a forma crassa de fonemas, vocábulos e enunciados. O passo necessário previsto pelo postulado ontológico é que não se distinguem palavra e coisa senão por força da multiplicidade, já a arbitrariedade da relaçáo entre elas é negada pela experiência de transmissão da revelação, sempre a mesma e intocada pelo agenciamento humano. A Gramática, Vyākaraṇa, é a chave dessa experiência justamente a partir da manutenção material da tradição revelada, de que, em todas as suas elaboraçóes teóricas, jamais de desprende. 


\section{Referencias}

Aklujkar, A. (1993). Once again on the authorship of the Vākyapadiya-vrtti. Asiatische Studien / Etudes Asiatiques $47(1), 45-57$.

Aklujkar, A. (s.d.). Trikāṇ̣̂̄, Book 1: Brahma-kāṇ̣̣a. [Edição inédita do $1^{\circ}$ livro do $\mathrm{Vp}$, disponibilizada pessoalmente pelo editor]

Aprigliano, A. (2014). Da palavra [Vākyapadīya]. São Paulo: Unesp.

Biardeau, M. (1964). Vākyapadīya Brahma-kāṇda avec la Vrtti de Harivrsabha. Traduction, introduction et notes. Paris: De Boccard.
Bronkhorst, J. (1988). Etudes sur Bhartrohari, 1: L'auteur e la date de la Vrtti. Bulletin d'etudes indiennes, 6, 105-143.

Rau, W. (1977). Bhartroaris' Vākyapadìya. Die Mūla-kārikās nach der Handschriften herausgegeben und mit ein Pada-index versehen. Wiesbaden: Franz Steiner.

Subramania-Iyer, K. A. (1966). The Vākyapadìya of Bhartrhari with the commentaries Vrtti and Paddhati of Vrșabhadeva. Puna: Deccan College. 